\title{
Preface to the Special Issue on "Climate Changes and Their Impacts in Taiwan"
}

\author{
Ke-Sheng Cheng ${ }^{1, *}$, Cheng-Ta Chen ${ }^{2}$, Huang-Hsiung Hsu ${ }^{3}$, Keh-Chia Yeh ${ }^{4}$, and Lee-Yaw Lin ${ }^{5}$ \\ ${ }^{1}$ Department of Bioenvironmental Systems Engineering, National Taiwan University, Taipei City, Taiwan, R.O.C. \\ ${ }^{2}$ Department of Earth Sciences and Institute of Marine Environmental Science and Technology, National Taiwan Normal \\ University, Taipei City, Taiwan, R.O.C. \\ ${ }^{3}$ Research Center for Environmental Change, Academia Sinica, Taipei City, Taiwan, R.O.C. \\ ${ }^{4}$ Department of Civil Engineering, National Chiao Tung University, Hsinchu, Taiwan, R.O.C. \\ ${ }^{5}$ National Science and Technology Center for Disaster Reduction, New Taipei City, Taiwan, R.O.C.
}

Received 14 November 2016, revised 16 November 2016, accepted 17 November 2016

Citation: Cheng, K. S., C. T. Chen, H. H. Hsu, K. C. Yeh, and L. Y. Lin, 2016: Preface to the special issue on "Climate changes and their impacts in Taiwan". Terr. Atmos. Ocean. Sci., 27, I-II, doi: 10.3319/TAO.2016.11.17.01

Climate change and global warming may no longer be a matter of faith. A huge number of researches on climate change and global warming have been reported since the late $20^{\text {th }}$ century. The Fifth Annual Report (AR5) from the Intergovernmental Panel on Climate Change (IPCC) released in 2013 and 2014 reports an observed increase of $0.85^{\circ} \mathrm{C}$ in the global average temperature during 1880 - 2012 with an accelerating increase rate in recent years. Many events and evidences around the world also reveal that extreme climates, such as heat waves, droughts, and torrential rainfalls are changing in terms of their frequency of occurrences and severity.

For a small region like Taiwan, developing high-resolution climate projections for various impact assessments remains a challenging task. In coping with this challenge, the Ministry of Science and Technology, R.O.C. has been supporting a national climate change project "The Taiwan Climate Change Projection and Information Platform Project (TCCIP)" since 2009. The TCCIP has compiled a large dataset of historical weather and climate records and outputs from many climate models. Through data digitization, assimilation, spatial interpolation, and statistical/dynamic downscaling, gridded meteorological datasets with high spatial and temporal resolutions were produced. Data generated by the TCCIP have been applied for various climate change impact assessments, including flood inundation, drought, landslide, and coastal disasters.

The TCCIP is coordinated by the National Science and Technology Center for Disaster Reduction (NCDR). In addi-

\footnotetext{
* Corresponding author

E-mail:rslab@ntu.edu.tw
}

tion to NCDR, many researchers at universities, government departments, and research institutes also undertook certain tasks in support of TCCIP. One major aim of the TCCIP is to bridge the gaps between the data producers and end users and convey useful and correct information regarding the climate projection data to the end users of various disciplines. To achieve this goal, TCCIP forms four research teams with specific research objectives and missions. Research Team 1 focuses on compiling observed datasets, constructing calibrated and gridded datasets and conducting model output analyses. Research Team 2 aims to produce downscaled data through statistical and dynamic downscaling. Research Team 3 develops modeling and simulation techniques for climate change impact assessments and their uncertainties in various applications. A newly established Research Team 4 focuses on data services, communication and promotion of TCCIP data usages.

This special issue presents major scientific evidences and insightful findings of the TCCIP and other research works using TCCIP data from various fields. Major themes and subtopics of this special issue are summarized as follows.

\section{Climate Change and Extremes in Taiwan}

(1) Climate variability reflected by the winter temperature (Lu et al. 2016).

(2) Climate variation of the East Asian Winter Monsoon (Kao et al. 2016).

(3) Extreme rainfall evaluation using a standardized index (Tung et al. 2016).

(4) Summer convective afternoon rainfall projection (Huang et al. 2016a, b). 


\section{Climate Projection and Downscaling Techniques}

(1) Bias correction of MRI-WRF dynamic downscaled hourly typhoon rainfall and daily solar radiation ( $\mathrm{Su}$ et al. 2016).

(2) Constructing a multi-scalar drought index 1-km gridded dataset in Taiwan (Weng 2016).

(3) Typhoon activities over the Western North Pacific Region (Tsou et al. 2016).

\section{Assessing the Impact and Risk of Climate Change in Taiwan}

(1) Landslide impact (Wu et al. 2016).

(2) Changes in river beds (Chao et al. 2016).

(3) Flood losses under projected extreme weather events (Wei et al. 2016).

(4) Changes in stream flow at catchment scale (Chen et al. 2016)

We are grateful to the TAO editorial office for their superb support and assistance during the editing process. Our sincere appreciations also extend to all contributing authors and reviewers for their enthusiasm and dedication, which have made this special issue a reality.

\section{REFERENCES}

Chao, Y. C., H. C. Li, J. J. Liou, and Y. M. Chen, 2016: Extreme bed changes in the Gaoping River under climate change. Terr. Atmos. Ocean. Sci., 27, 717-727, doi: 10.3319/TAO.2016.06.30.03. [Link]

Chen, Y. J., J. L. Chu, C. P. Tung, and K. C. Yeh, 2016: Climate change impacts on streamflow in Taiwan catchments based on statistical downscaling data. Terr. Atmos. Ocean. Sci., 27, 741-755, doi: 10.3319/ TAO.2016.07.20.01. [Link]

Huang, W. R., Y. H. Chang, C. T. Cheng, H. H. Hsu, C. Y. Tu, and A. Kitoh, 2016a: Summer convective afternoon rainfall simulation and projection using WRF driven by global climate model. Part I: Over Taiwan. Terr. Atmos. Ocean. Sci., 27, 659-671, doi: 10.3319/ TAO.2016.05.02.01. [Link]

Huang, W. R., Y. H. Chang, H. H. Hsu, C. T. Cheng, and C.
Y. Tu, 2016b: Summer convective afternoon rainfall simulation and projection using WRF driven by global climate model. Part II: Over South China and Luzon. Terr. Atmos. Ocean. Sci., 27, 673-685, doi: 10.3319/ TAO.2016.05.02.02. [Link]

Kao, P., C. Hung, and H. H. Hsu, 2016: Decadal variation of the East Asian Winter Monsoon and Pacific Decadal Oscillation.Terr. Atmos. Ocean. Sci., 27, 617-624, doi: 10.3319/TAO.2016.05.29.01. [Link]

Lu, M. M., Y. M. Cho, Y. C. Lin, and N. E. Huang, 2016: Atlantic and Pacific multidecadal variability influence on Taiwan winter temperature centennial trend during the period 1911 - 2010. Terr. Atmos. Ocean. Sci., 27, 605-615, doi: 10.3319/TAO.2016.06.30.02. [Link]

Su, Y. F., C. T. Cheng, J. J. Liou, Y. M. Chen, and A. Kitoh, 2016: Bias correction of MRI-WRF dynamic downscaling datasets. Terr. Atmos. Ocean. Sci., 27, 649657, doi: 10.3319/TAO.2016.07.14.01. [Link]

Tsou, C. H., P. Y. Huang, C. Y. Tu, C. T. Chen, T. P. Tzeng, and C. T. Cheng, 2016: Present simulation and future typhoon activity projection over western North Pacific and Taiwan/East Coast of China in 20-km HiRAM climate model. Terr. Atmos. Ocean. Sci., 27, 687-703, doi: 10.3319/TAO.2016.06.13.04. [Link]

Tung, Y. S., C. T. Chen, S. K. Min, and L. Y. Lin, 2016: Evaluating extreme rainfall changes over Taiwan using a standardized index. Terr. Atmos. Ocean. Sci., 27, 705-715, doi: 10.3319/TAO.2016.06.13.03. [Link]

Wei, H. P., H. C. Li, K. C. Yeh, J. J. Liou, Y. M. Chen, and H. J. Lin, 2016: Using structural measures to reduce flood losses in a future extreme weather event. Terr. Atmos. Ocean. Sci., 27, 757-767, doi: 10.3319/ TAO.2016.07.14.02. [Link]

Weng, S. P., 2016: Constructing a 1-km gridded multiscalar drought index dataset (1960 - 2012) in Taiwan based on the standardized precipitation evapotranspiration index-SPEI. Terr. Atmos. Ocean. Sci., 27, 625648, doi: 10.3319/TAO.2016.06.13.02. [Link]

Wu, T., H. J. Shih, H. C. Li, Y.F. Su, and Y. M. Chen, 2016: Landslide impact assessment using projection rainfall data from climate change scenario. Terr. Atmos. Ocean. Sci., 27, 729-740, doi: 10.3319/TAO.2016.07.18.03. [Link] 